\title{
Proportions, characters and chronologies: their contribution to systematic paleontology. A rebuttal to Furió and Pons-Monjo
}

\author{
Juan Rofes, Pere Bover, Gloria Cuenca-Bescós, and Josep Antoni Alcover
}

\begin{abstract}
The comment by Furió and Pons-Monjo is an attempt to invalidate the new species Nesiotites rafelinensis recently described by Rofes et al. and to place it in synonymy with $N$. ponsi or a closely related form ( $N$. aff. ponsi and/or $N$. cf. ponsi). Through detailed argumentation, the use of proportions instead of lengths, the re-analysis of the characters questioned by Furió and Pons-Monjo, and the consideration of the chronology and the evolution of ecological communities, we rebut Furió and Pons Monjo's conclusions and confirm the status of $N$. rafelinensis as a valid and distinct species represented by the specimen of Caló den Rafelino (Mallorca, Spain).
\end{abstract}

Juan Rofes. Departamento de Estratigrafía y Paleontología, Facultad de Ciencia y Tecnología, Universidad del País Vasco. Sarriena s/n, 48940 Leioa, Spain. juan.rofes@ehu.es and Grupo Aragosaurus-IUCA, Área de Paleontología, Departamento de Ciencias de la Tierra, Universidad de Zaragoza, 50009 Zaragoza, Spain

Pere Bover. Institut Mediterrani d'Estudis Avançats, Cr Miquel Marqués 21, 07190 Esporles, Mallorca, Balearic Islands.

and

Research Associate, Division of Vertebrate Zoology/Mammalogy, American Museum of Natural History, Central Park West at 79th Street, 10024 New York, USA. perebover@imedea.uib-csic.es

Gloria Cuenca-Bescós. Grupo Aragosaurus-IUCA, Área de Paleontología, Departamento de Ciencias de la Tierra, Universidad de Zaragoza, 50009 Zaragoza, Spain. cuencag@unizar.es Josep Antoni Alcover. Institut Mediterrani d'Estudis Avançats, Cr Miquel Marqués 21, 07190 Esporles, Mallorca, Balearic Islands

and

Research Associate, Division of Vertebrate Zoology/Mammalogy, American Museum of Natural History, Central Park West at 79th Street, 10024 New York, USA. jaalcover@imedea.uib-csic.es

KEYWORDS: New species; anatomy; Caló den Rafelino; Mallorca; Pliocene; Nesiotites

Rofes, Juan, Bover, Pere, Cuenca-Bescós, Gloria, and Alcover, Josep Antoni. 2013. Proportions, characters and chronologies: their contribution to systematic paleontology. A rebuttal to Furió and Pons-Monjo, Palaeontologia Electronica Vol. 16, Issue 2; 20A; 5p; palaeo-electronica.org/content/2013/507-rebuttal-to-furio-and-pons-monjo 
The comment by Furió and Pons-Monjo (2013) is a criticism of the description of the new fossil species Nesiotites rafelinensis by Rofes et al. (2012). The key point of their critique was the supposed lack of sufficient traits supporting the definition of a new species with a single specimen. The authors concluded that the different characters used in our diagnosis are shared with other species of Nesiotites or are too irrelevant to be diagnostic. They argued that the material from Caló den Rafelino (CDR) would be better referred to $N$. ponsi or to a closely related form ( $N$. aff. ponsil $N$. cf. ponsi).

In general terms, the note by Furió and PonsMonjo is an interesting and well-illustrated discussion of the intraspecific variability of two species of the genus Nesiotites: $N$. hidalgo and $N$. aff. ponsi (the latter is the name used by Furió and PonsMonjo for the Nesiotites specimens from Pedrera de s'Onix [PO]). These taxa were both endemic to the Balearic Islands during the Quaternary. In our opinion, however, these authors fail in their major objective of invalidating the new species $N$. rafelinensis. We agree with the authors in that it is better to have larger number of specimens than single specimens, but we strongly disagree with many specific aspects of their analysis and conclusions.

With regard to size measurements, Furió and Pons-Monjo (2013) presented a series of box-plot graphics in their figure 1 , which they used to argue that all the dental measurements of the CDR specimen fall within the variability range of $N$. ponsi. But how can the authors be so sure of the variability of $N$. ponsi when, for many samples, the number of $N$. ponsi sensu stricto are equal to two or fewer individuals, despite having analyzed thousands of specimens of $N$. hidalgo and $N$. aff. ponsi?

Another important issue should be raised here: Furió and Pons-Monjo have relied entirely on single linear measurements (lengths) in their analysis of Nesiotites teeth. In our original article (Rofes et al., 2012), we analysed variability in proportions (size + shape) of specimens (c.f., the PCA in figure 5 ), which is, to our knowledge, much more reliable at discriminating differences between species than purely linear distances (see Rofes and CuencaBescós, 2009). Therefore, Furió's and PonsMonjo's power to refute the conclusions of Rofes et al. (2012) is diminished, especially with the questions about the taxonomic affinity of their $N$. ponsi sample.

What is notable about the PCA by Rofes et al. (2012) is that when many variables are includedespecially those from the mandible-the CDR specimen is similar to the $N$. aff. ponsi distribution, but, as recognized by Furió and Pons-Monjo, it falls outside the convex hull of all other taxa. When only single linear measurements are considered does the CDR specimen fall within the range of $N$. ponsi, as shown in fig. 4 of Rofes at al. (2012) and some of the box-plots from of fig. 1 of Furió and PonsMonjo (2013).

Furió and Pons-Monjo specifically questioned the accuracy of our m3 measurements on the grounds that this tooth was broken. While it is true that the $\mathrm{m} 3$ of the CDR specimen is incomplete, only the last segment of the talonid is missing: the total length of the tooth can be easily and confidently estimated with the alveolus. Regardless, the measurement of the width of the $\mathrm{m} 3$ (taken on the trigonid) by Rofes et al. (2012) is unaffected by the breakage, but despite this Furió and Pons-Monjo assigned a new measurement in support of their referral of the specimen to $N$. rafelinensis (i.e. in the last box-plot graphic of their fig.1, the CDR item falls outside the range of variation of Nesiotites aff. ponsi).

In regard to pigmentation and morphological characters, our primary and most substantial objection that we have to Furió and Pons-Monjo critique is that they have not inspected material of $N$. ponsi directly. The authors claim that after a thorough study of thousands of specimens, they found that the teeth of all Balearic Nesiotites are weakly pigmented or they even look completely white to the naked eye. After a detailed review of specimens of $N$. ponsi, N. aff. ponsi, N. hidalgo, $N$. meloussae, Asoriculus gibberodon and A. similis, we have recorded some highly pigmented specimens of $N$. ponsi from Crulls de Cap Farrutx, and of $N$. meloussae from Barranc de Binigaus. The two examples of white teeth given by the authors (figs. 2.4 and 2.7) correspond to markedly worn items if compared to figs. 2.1 and 2.2 of the same plate. The loss of pigment is implied by these exemplars. The teeth of the CDR specimen are not as worn as those in figs. 2.4 and 2.7 of the authors, and they have little pigment, as in the $\mathrm{m} 1$ of figs. 2.1 and 2.2 of the authors. Therefore, if there exists a few highly pigmented specimens, others with less pigment, and even some with no pigment at all, then it is reasonable to state that: 1) The pigmentation decreases as the teeth wear, and/or 2) the loss of pigment is due to taphonomic reasons (e.g., composition of the soil, a bias towards old individuals in the samples, etc). Rofes et al. (2012) do not say whether the colouration of $N$. rafelinensis is different from that of other specimens of 
Nesiotites. The pigment is a character mentioned as one among others being useful to distinguish the new species.

In relation to the cuspule and the lingual crest on the posterolingual basin of $\mathrm{p} 4$, the characters are perfectly discernible in figs. $3 \mathrm{~A}$ and $5 \mathrm{~A}$ of Furió and Pons-Monjo (as they are in figs. 3.2 and 3.3 of Rofes et al., 2012), and they are more developed than in $N$. rafelinensis, as is to be expected in specimens of $N$. aff. ponsi (fig. 3A of the authors) and $N$. hidalgo (fig. $5 \mathrm{~A}$ of the authors) according to Rofes et al. (2012). The conclusion that "this trait is therefore not sufficient for future taxonomic identification" seems, therefore, wrong.

According to Furió and Pons-Monjo, "the p4 [of Nesiotites] usually displays a broad and welldefined curved cingulid (figure 2), not different to that of $N$. rafelinensis", but, in our opinion, none of the specimens shown in that figure has a cingulum broader than the item of CDR (Rofes et al., 2012: fig. 3). To support our assertion, we have taken some measurements, specifically, the vertical distance from the tip of the posterior cusp to the lower border of the tooth (lateral view) and the width of the cingulum in that same vertical line of the p4 both of $N$. rafelinensis (fig. 3.1 of Rofes et al., 2012) and $N$. aff. ponsi (figs. 2.1 and 2.2 of Furió and Pons-Monjo, 2013). The result of calculating the proportion between those measurements is that the cingulum of the CDR item occupies more than $32 \%$ of the vertical line, and the cingula of the $N$. aff ponsi specimens do not exceed the $25 \%$ of it. We have chosen the specimens of figs 2.1 and 2.2 of Furió and Pons-Monjo because those are the only two of the plate with discernible cingula.

Furió and Pons-Monjo (2013) stated that "lingual cingulids of the lower molars in all our specimens tend to be (when discernible) rather straight and broad, as in the holotype of this new species", but, as it can be seen in fig. 3.3 of Rofes et al. (2012), the cingula of $\mathrm{m} 1$ and $\mathrm{m} 2$ are clearly quite undulated.

At this point, we would like to introduce a new character that seems to isolate $N$. rafelinensis from the rest of Nesiotites species or at least from those depicted by Furió and Pons-Monjo (2013), i.e. N. hidalgo and $N$. aff. ponsi: the posterobuccal corner of the crown of the p4 is much more elongated in these latter species than in the CDR item (compare fig. 3.1 of Rofes et al. [2012] with figs. 2.1, 2.2, 2.4, 2.5B, 2.6A, and 2.7 of Furió and Pons-Monjo: the difference is more than evident). Moreover, we did some calculation: the proportion between the total length of the $\mathrm{p} 4$ and the distance from the tip of the posterior cusp to the extreme of the posterobuccal corner (lateral view) is of $60 \%$ of the total length of the tooth occupied by the posterobuccal elongation in $N$. rafelinensis, and a range of $65-73 \%$ in $N$. aff. ponsi, and of $73-75 \%$ in N. hidalgo. More measurements need to be done, but a chronological trend of progressive elongation of the posterobuccal corner of the p4 in Nesiotites species is glimpsed.

The two characters with which we agree that is advisable to have caution, at least until more material of $N$. rafelinensis is described, are the position of the mental foramen and the absence of accessory cusps in $\mathrm{m} 1$ and $\mathrm{m} 2$. However, if we carefully compare the position of the mental foramen in $N$. rafelinensis with that in the two items having it more forwardly placed in the plate of Furió and Pons-Monjo (figs. 2.4 and 2.5B), we will see that the foramen in the CDR specimen is slightly forward, as correctly observed by Rofes et al. (2012). The recently discovered soricine material from Na Burguesa-1 (Mallorca, late Miocene/early Pliocene in age: Bover et al., 2013: fig. 3a) can shed light on the validity of these two supposedly doubtful characters. It is striking that, in the two new mandibles, provisionally attributed to Nesiotites/Asoriculus, there is a complete absence of accessory cusps in $\mathrm{m} 1-\mathrm{m} 2$, the buccal cingula is almost straight, and the mental foramen has a very forward position. One of the specimens is not especially worn and the other has completely lost (at least to the naked eye) its tooth pigmentation.

Another remarkable aspect: nearly $3 \mathrm{Myr}$ separate $N$. rafelinensis and the oldest specimens of N. ponsi (see fig. 1 of Rofes et al., 2012). The Nesiotites clade, from $N$. ponsi to $N$. hidalgo includes different populations that can be perfectly isolated along time. The hypothesis that no evolution occurred in the clade before $N$. ponsi, when all the remaining species of the Balearic fauna changed (Bover et al., 2008, 2013) is lame. Moreover, the faunal association of CDR is much more diverse (five mammals -including $N$. rafelinensis- and six reptiles) than that of Crulls de Cap Farrutx (three mammals -including N. ponsi-, two reptiles), showing radically different ecological communities (Bover et al., 2013). The taxonomical continuity would be then even more difficult to explain.

Additionally, in a previous paper (Pons-Monjo et al., 2010) these authors questioned the use of the name "Asoriculus hidalgo" (instead of "Nesiotites hidalgo") by Bover and Alcover (2008) with no arguments to support their claims. Nevertheless, in the same paper they avoid commenting the previ- 
ous use of "Asoriculus hidalgo" by Furió (2007), who explicitly considered Nesiotites to be a "problematic genus" and who used $A$. hidalgo without any background validation of it. Also, there are no comments in Pons-Monjo et al. (2010) of the use of Soriculus hidalgo by Moyà Solà et al. (1999). It is surprising the commentary of Furió and PonsMonjo (2013) that Rofes et al. (2012) would have benefitted from knowing the variability of $\mathrm{PO}, \mathrm{CC}$ and $\mathrm{BB}$ specimens, while avoiding to mention that Furió and Pons-Monjo (2013) would have certainly benefitted from the direct study of the Nesiotites rafelinensis specimen to write their criticism. In the same sense, it is striking that, while Pons-Monjo et al. (2012) demonstrate that the PO Nesiotites populations are identical to Nesiotites meloussae (identifying therefore a valid scientific name for it) Furió and Pons-Monjo (2013) avoid using the name proposed by themselves or use it between brackets (in their figure 1), in contra of their previous establishment. These kind of inconsistencies do not facilitate scientific progress.

Finally, we accept that the recognition of a new species based on a single specimen is a problematic task. Nevertheless, and above all, the diagnosis of $N$. rafelinensis is based on the combination of different morphometrical and morphological traits. This unique combination has not been recorded in the rest of Nesiotites species. The finding of a single individual of $N$. ponsi with the combination of characters used to define $N$. rafelinensis would be a convincing proof of their identity. As far as after the study of more than 4000 specimens of Nesiotites spp. (Pons-Monjo et al., 2012) such a specimen has not been retrieved, it should be stated that the identity of $N$. ponsi and $N$. rafelinensis has not been demonstrated.

Inadequate proposals inevitably lead to wrong palaeontological interpretations. The suggestion by Furió and Pons Monjo (2013) of an affinity between the CDR specimen and those from Pedrera de s'Onix ( $N$. aff. ponsi), together with the previous proposal of identifying PO Nesiotites with $N$. meloussae by Pons-Monjo et al. (2012) produces an impossible phylogenetic lineage (i.e., $N$. meloussae - N. ponsi - N. meloussae - N. hidalgo).

To summarize, our primary objections to Furió's and Pons-Monjo's critique are: 1) the authors propose to synonymise the recently described $N$. rafelinensis with $N$. ponsi, but they have not directly inspected items of this latter species (or at least this is what can be inferred from the text); in measurements and morphology they completely rely on published literature; 2 ) they rely exclusively on univariate linear measurements and not proportions (size + shape) as support for their assertions, which is risky when dealing with new species; 3) they critiqued six out of seven of the characters proposed by Rofes et al. (2012) to define $N$. rafelinensis, but, as argued above, only two of those six characters can be considered to be dubious thus require corroboration with new material; moreover, we offer two additional characters in support of the distinction of $N$. rafelinensis: the width of $\mathrm{m} 3$ and the short elongation of the posterobuccal corner of $\mathrm{p} 4 ; 4)$ those authors used a univariate analysis of characters defining $N$. rafelinensis, arguing that this provided evidence that these characters fell within the range of variation of two other Nesiotites species, i.e. N. hidalgo and $N$. aff. ponsi ( $=N$. meloussae), however, the diagnosis of $N$. rafelinensis is based on a multivariate combination of characters that is unique for that species; 5 ) the authors disregard chronology and ecological context associated with the species and/or localities: N. rafelinensis (Caló den Rafelino) is older than $N$. ponsi (Crulls de Cap Farrutx), and much older than $N$. aff. ponsi (Pedrera de s'Onix) and $N$. hidalgo (Cova de Canet).

Our conclusion is therefore that there is not evidence enough to reject the validity of $N$. rafelinensis and to put it in synonymy with $N$. ponsi or $N$. cf. ponsi (or even with $N$. aff. ponsi) as proposed by Furió and Pons-Monjo (2013). New findings from Na Burguesa-1 (Bover et al., 2013) will surely contribute to clarify this controversy in a not so distant future.

\section{ACKNOWLEDGEMENTS}

Juan Rofes has a "Juan de la Cierva" postdoctoral Research Fellowship (JCl-2010-06148) of the Ministerio de Economía y Competitividad of Spain. Pere Bover had a contract JAE-DOC (CSIC) of the program "Junta para la Ampliación de Estudios". This paper is included in the Projects CGL2012-38087, CGL2012-38434-C03-01, and GIU12/35 of the University of the Basque Country UPV/EHU. The English edition of Dr. P. David Polly must be also recognized.

\section{REFERENCES}

Bover, P., Quintana, J., and Alcover, J.A. 2008. Three islands, three worlds: Paleogeography and evolution of the vertebrate fauna from the Balearic Islands. Quaternary International, 182:135-144. 
Bover, P., Rofes, J., Bailon, S., Agustí, J., Cuenca-Bescós, G., Torres, E., and Alcover, J.A. 2013. The late Miocene/early Pliocene vertebrate fauna from MalIorca (Balearic Islands, Western Mediterranean): an update. Integrative Zoology DOI: 10.1111/17494877.12049.

Furió, M. 2007. Los insectívoros (Soricomorpha, Erinaceomorpha, Mammalia) del Neógeno Superior del Levante Ibérico. Unpublished PhD Thesis, Universitat Autònoma de Barcelona, Spain. Available at: tesisenred.net/bitstream/handle/10803/3446/ mfb1de1.pdf?sequence $=1$

Furió, M. and Pons-Monjo, G. 2013. The use of the species concept in paleontology. Comment on "Nesiotites rafelinensis sp. nov., the earliest shrew (Mammalia, Soricidae) from the Balearic Islands, Spain" by Rofes et al., 2012. Paleontologia Electronica, 16 (2): 16A, 7p.

Moyà-Solà, S., Quintana, J., Alcover, J.A., and Köhler, M. 1999. Endemic Islands Faunas of the Mediterranean Miocene, p. 435-442. In Rössner, G.E. and Heissig, K. (eds.), The Miocene Land Mammals of Europe. Verlag, Dr. Friedrich Pfeil, München.
Pons-Monjo, G., Furió, M., and Moyà-Solà, S. 2010. The genus Nesiotites (Soricidae, Insectivora, Mammalia) in the Balearic Islands: state of the art. Cidaris, 30: 253-258.

Pons-Monjo, G., Moyà-Solà, S., and Furió, M. 2012. New data on the origin of Nesiotites (Soricidae, Mammalia) in Menorca (Balearic Islands, Spain). Comptes Rendus Palevol, 11:393-401.

Rofes, J., Bover, P., Cuenca-Bescós, G., and Alcover, J.A. 2012. Nesiotites refelinensis sp. nov., the earliest shrew (Mammalia, Soricidae) from the Balearic Islands, Spain. Palaeontologia Electronica, 15 (1):8A, $12 p$.

Rofes, J., and Cuenca-Bescós, G. 2009. A new genus of red-toothed shrew (Mammalia, Soricidae) from the Early Pleistocene of Gran Dolina (Atapuerca, Burgos, Spain), and a phylogenetic approach to the Eurasiatic Soricinae. Zoological Journal of the Linnean Society, 155:904-925. 